\title{
Frailty Syndrome in Older Adults and Related Sociodemographic Factors in the North of Iran: A Population-Based Study
}

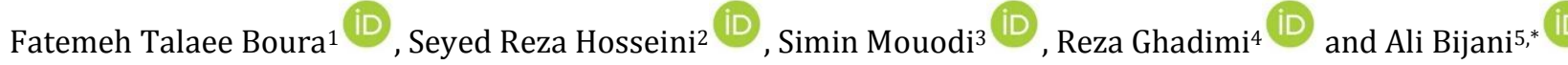 \\ ${ }^{1}$ MD, Faculty of Medicine, Babol University of Medical Sciences, Babol, Iran \\ 2 MD, Professor in Social Medicine, Social Determinants of Health Research Center, Health Research Institute, Babol University of Medical Sciences, Babol, Iran \\ 3 MD, MPH, PhD, Assistant Professor in Research in Clinical Sciences, Social Determinants of Health Research Center, Health Research Institute, Babol University \\ of Medical Sciences, Babol, Iran \\ ${ }^{4} \mathrm{MD}$, PhD, Associate Professor in Clinical Nutrition, Social Determinants of Health Research Center, Health Research Institute, Babol University of Medical \\ Sciences, Babol, Iran \\ 5 MD, PhD, Assistant Professor in Epidemiology, Social Determinants of Health Research Center, Health Research Center, Babol University of Medical Sciences, \\ Babol, Iran
}

* Corresponding author: Ali Bijani, Social Determinants of Health Research Center, Health Research Center, Babol University of Medical Sciences, Babol, Iran. Tel: +981132190557; Email: alibijani@yahoo.com

Received 2020 November 05; Revised 2020 November 19; Accepted 2020 December 08

\begin{abstract}
Background: The global incidence rate of frailty syndrome among older adults aged 60 years and over has been estimated to be 43.4 cases per 1000 persons/years.

Objectives: This study aimed to determine the prevalence of pre-frailty and frailty syndromes in community-dwelling older adults and assess the correlated sociodemographic factors.

Methods: All elderly people recruited in the second phase of the Amirkola Health and Ageing Cohort Project, including 2135 older adults aged $\geq 60$ years living in Amirkola, North of Iran, were invited to participate in this study using the census method. The standard "FRAIL" scale was used to assess the frailty syndrome. The individuals who obtained a score of three or more and one or two were classified as frail and pre-frail cases, respectively.

Results: Totally, 2010 older adults with a mean age of $70.41 \pm 7.65$ years were included in this study. Out of them, 672 (33.4\%; $95 \%$ CI: $31.37-35.50 \%)$ cases met the criteria for frailty syndrome, and $874(43.5 \%)$ individuals were regarded as pre-frail. The prevalence of frailty was significantly higher in females (50.8\%; 95\% CI: 47.58-54.05\%), compared to males (18.7\%; 95\% CI: 16.41-21.05\%). Multivariate logistic regression analysis revealed that age $\geq 85$ (OR=7.27; 95\% CI: 4.12-24.46) and female gender (OR=2.67; 95\% CI: 2.30 9.95) had the highest effect on frailty in older adults.

Conclusion: One out of every three elderly people (aged $\geq 60$ ) in Amirkola, North of Iran, had frailty syndrome. Older age, female gender, lower education level, low level of satisfaction with income, marital status (single), living alone, and unemployment increas ed the risk of frailty in older adults.

Keywords: Asthenia, Debility, Elderly, Frailty, Muscle weakness
\end{abstract}

\section{Background}

Frailty syndrome (FS) is a clinically-recognizable state resulted from the accumulation of some comorbidities, such as reduced energy, low physical activity, unintentional weight loss, muscular weakness, and slower walking that can be observed with a higher incidence in older adults $(1,2)$. When there are one or two out of the mentioned deficits, the patient can be considered as a pre-frail person (1).

Since reduced immunity to stress factors and decreased functional reserves have been considered the important pathophysiologic mechanisms for the occurrence of this disorder, FS might lead to different adverse complications (2-4). Falls, fractures, dementia, and disability have been reported to be higher in frail individuals (5).

The global incidence rate of frailty among older adults $(\geq 60)$ has been estimated to be $43.4(95 \%$ CI: 37.3-50.4) cases per 1000 person/years (6). Moreover, its worldwide prevalence has been ranged from $4.0 \%$ to $59.1 \%$ in older adults aged $\geq 65$ years, depending on the criteria used for FS definition (5). The prevalence of FS in low and middle-income countries has been reported to be $17.4 \%$ in people aged 60 years and over, which is higher than that in high-income countries $(10.7 \%)(7,8)$. Frailty is more common in females, compared to males $(6,8)$.

Frailty syndrome has important impacts on the health-care system $(5,9)$. The overall mortality risk in frail individuals is 3.49 (2.09-5.82) times higher than that in non-frail individuals (10). Furthermore, a reciprocal relationship has been found between the frailty syndrome and chronic disorders. Multiple chronic diseases are more prevalent in frail people, and frailty can be an outcome of the advanced stage of some disorders, such as malignancies, chronic renal diseases, and heart failure $(4,5,11)$. It should be noted that decreased quality of life is another impact of frailty syndrome $(1,3,5)$.

The increasing elderly population in Iran is comparable to that in many other countries across 
the world $(12,13)$. Therefore, the issue of frailty and the identification of frail adults has been notified in recent years in Iranian studies $(14,15)$.

\section{Objectives}

This study aimed to determine the prevalence of frailty and pre-frailty in community-dwelling older adults and assess its association with sociodemographic factors.

\section{Methods}

This observational study was a part of the Amirkola Health and Ageing cohort Project (AHAP) $(12,16)$ and was carried out as a cross-sectional study from 2019 to 2020. All elderly people recruited in the second phase of the AHAP cohort project, including 2135 older adults aged 60 years and over living in Amirkola, north of Iran, were invited to participate in the study. No sampling was conducted, and all the elderly people were recruited in the study by a census method. Individuals whose related data were incomplete and who were unable to answer questions (due to severe speech impairment or severe hearing loss), as well as patients with cognitive impairment, were excluded from the study.

Sociodemographic characteristics including age, gender, level of education, marital status, living status, and occupation have been recorded through direct interviews with the elderly or their close relatives. In addition, the question of "How satisfied are you with your or your family's monthly income?" was asked from the participants, and the person's response was rated on a 5-point Lickert scale from very low to very high.

The standard "FRAIL" scale was used to measure the frailty $(17,18)$. This questionnaire includes five items to evaluate the person in terms of sufficient energy to do activities, ability to climb stairs, ability to walk without any assistance, identify other illnesses in the elderly, and unwanted weight loss in the previous six months. Each item was scored using zero or one (lack of enough energy to do activities $=1$; enough energy=0). Out of the total scores of the responses to these five questions, people who have obtained a score of three or more are known as frail, and the individuals who get a score of one or two are considered pre-frail individuals (17).

All participants were informed about the research through a Persian informed consent form. The study protocol was approved by the Ethics Committee of Babol University of Medical Sciences, Babol, Iran (IR.MUBABOL.HRI.REC.1397.144). The data were analyzed in SPSS software (version18) through the Chi-square test and logistic regression analysis to determine the role of different characteristics affecting the elderly's frailty.

\section{Results}

Totally, 2010 older adults with the mean age of $70.41 \pm 7.65$ (age range:60-99) years, including 1089 (54.2\%) males and 921 (45.8\%) females were recruited in the research. Most of the participants $(\mathrm{n}=1204 ; 59.9 \%)$ were illiterate or had primaryschool education level $(\mathrm{n}=429 ; 21.3 \%)$. Moreover, $1658(82.5 \%)$ cases were married and 1814 (90.2\%) individuals were living with others (not alone). Furthermore, 604 (29.9\%) cases were in the agegroup of 65-69 years, and two-thirds of the participants had very low $(\mathrm{n}=473 ; 23.5 \%)$ or low $(n=795 ; 39.6 \%)$ level of satisfaction with their monthly income.

Out of the total participants in this study, 672 (33.4\%; 95\% CI: 31.37-35.50\%) cases met the criteria for frailty syndrome, and 874 (43.5\%) individuals were regarded as pre-frail. The prevalence of frailty was significantly higher in females (50.8\%; 95\% CI: 47.58-54.05\%), compared to males (18.7\%; 95\% CI: $16.41-21.05 \%)$. Furthermore, the prevalence rates of pre-frailty were obtained at $40.3 \%$ and $46.2 \%$ in females and males, respectively $(\mathrm{P}<0.001)$. In addition, frailty showed an increase with increasing age, and $21.2 \%$ of the elderly in the age-group of 60-64 years had frailty syndrome, while this measure was estimated at $64.9 \%$ among those in the age-group of $\geq 85$ $(\mathrm{P}<0.001)$. Table 1 summarizes the association of frailty and pre-frailty with the examined variables. Moreover, the prevalence of FS in different agegroups divided into males and females has been presented in Figure 1.

\begin{tabular}{|c|c|c|c|c|c|}
\hline \multirow[b]{2}{*}{ Characteristics } & \multirow{2}{*}{$\begin{array}{c}\text { Total } \\
\text { Number } \\
\text { (percent) }\end{array}$} & \multicolumn{3}{|c|}{ Assessment of frailty syndrome } & \multirow{2}{*}{$\begin{array}{c}P- \\
\text { value }\end{array}$} \\
\hline & & $\begin{array}{c}\text { Normal } \\
\text { Number (percent) } \\
\end{array}$ & $\begin{array}{c}\text { Pre-frail } \\
\text { Number (percent) }\end{array}$ & $\begin{array}{c}\text { Frail } \\
\text { Number (percent) }\end{array}$ & \\
\hline $\begin{array}{l}\text { Level of education } \\
\text { Illiterate } \\
\text { Primary school } \\
\text { High school } \\
\text { College education }\end{array}$ & $\begin{array}{c}1204(59.9) \\
429(21.3) \\
256(12.7) \\
121(6.0)\end{array}$ & $\begin{array}{l}183(15.2) \\
121(28.2) \\
98(38.3) \\
62(51.2)\end{array}$ & $\begin{array}{c}506(42.0) \\
205(47.8) \\
115(44.9) \\
48(39.7)\end{array}$ & $\begin{array}{c}515(42.8) \\
103(24.0) \\
43(16.8) \\
11(9.1)\end{array}$ & $<0.001$ \\
\hline $\begin{array}{l}\text { Marital status } \\
\text { Single (Never married, divorced or widowed) } \\
\text { Married }\end{array}$ & $\begin{array}{c}352(17.5) \\
1658(82.5)\end{array}$ & $\begin{array}{c}39(11.1) \\
425(25.6)\end{array}$ & $\begin{array}{l}134(38.1) \\
740(44.6)\end{array}$ & $\begin{array}{l}179(50.9) \\
493(297)\end{array}$ & $<0.001$ \\
\hline
\end{tabular}




\begin{tabular}{lcccc}
\hline Table 1. Continued & & & \\
\hline Living status & $196(9.8)$ & $25(12.8)$ & $82(41.8)$ & $89(45.4)$ \\
Living alone & $1814(90.2)$ & $439(24.2)$ & $792(43.7)$ & $583(32.1)$ \\
Living with others & & & $<0.001$ \\
Occupation & $1090(54.2)$ & $112(10.3)$ & $433(39.7)$ & $545(50.0)$ \\
Housewife or unemployed & $218(10.8)$ & $59(27.1)$ & $128(58.7)$ & $31(14.2)$ \\
Farmer or worker & $464(23.1)$ & $200(43.1)$ & $199(42.9)$ & $65(14.0)$ \\
Employee or retired & $238(11.8)$ & $93(39.1)$ & $114(47.9)$ & $31(13.0)$ \\
Other & & & & $<0.001$ \\
Satisfaction with the monthly income & $473(23.5)$ & $60(12.7)$ & $179(37.8)$ & $234(49.5)$ \\
Very low & $795(39.6)$ & $190(23.9)$ & $354(44.5)$ & $251(31.6)$ \\
Low & $690(34.4)$ & $194(28.1)$ & $323(46.8)$ & $173(25.1)$ \\
Medium & $43(2.1)$ & $18(41.9)$ & $13(30.2)$ & $12(27.9)$ \\
High & $9(0.4)$ & $2(22.2)$ & $5(55.6)$ & $2(22.2)$ \\
Very high & & & & $<0.001$ \\
\hline
\end{tabular}

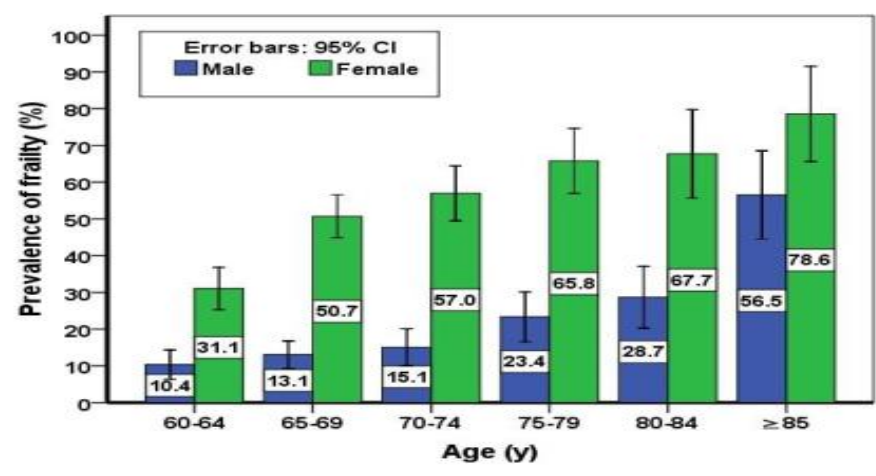

Figure 1. Prevalence of frailty syndrome in different age-groups of older adults, Amirkola, North of Iran

Multivariate logistic regression analysis results to evaluate the characteristics associated with frailty syndrome revealed that age $\geq 85$ (OR=7.27; 95\% CI:
4.12-24.46) and female gender (OR=2.67; 95\% CI: 2.30-9.95) had the highest effect on frailty in older adults (Table 2).

\begin{tabular}{|c|c|c|c|c|c|c|}
\hline \multirow{2}{*}{\multicolumn{2}{|c|}{ Characteristics }} & \multirow{2}{*}{$\begin{array}{l}\text { Met the frailty } \\
\text { criteria } \\
\text { Number } \\
\text { (percent) }\end{array}$} & \multicolumn{2}{|c|}{$\begin{array}{l}\text { Unadjusted logistic } \\
\text { regression analysis }\end{array}$} & \multicolumn{2}{|c|}{$\begin{array}{l}\text { Adjusted logistic } \\
\text { regression analysis }\end{array}$} \\
\hline & & & $\begin{array}{c}\text { Crude Odds ratio } \\
(95 \% \mathrm{CI})\end{array}$ & p-value & $\begin{array}{l}\text { Adjusted Odds } \\
\text { ratio }(95 \% \mathrm{CI})\end{array}$ & p-value \\
\hline Gender & $\begin{array}{l}\text { Male } \\
\text { Female }\end{array}$ & $\begin{array}{l}201(18.7) \\
468(50.8)\end{array}$ & $4.48(3.67-5.47)$ & $<0.001$ & $2.88(2.09-3.96)$ & $<0.001$ \\
\hline $\begin{array}{l}\text { Age-groups } \\
\text { (year) }\end{array}$ & $\begin{array}{l}60-64 \\
65-69 \\
70-74 \\
75-79 \\
80-84 \\
\geq 85\end{array}$ & $\begin{array}{l}102(21.2) \\
184(30.6) \\
128(34.5) \\
111(41.4) \\
75(42.4) \\
72(64.9)\end{array}$ & $\begin{array}{c}1 \text { (Reference) } \\
1.64(1.24-2.17) \\
1.96(1.45-2.67) \\
2.63(1.90-3.65) \\
2.74(1.89-3.96) \\
6.88(4.40-10.75)\end{array}$ & $\begin{array}{c}- \\
<0.001 \\
<0.001 \\
<0.001 \\
<0.001 \\
<0.001\end{array}$ & $\begin{array}{c}1 \text { (Reference) } \\
1.70(1.25-2.33) \\
1.98(1.40-2.80) \\
2.88(1.96-4.23) \\
2.86(1.85-4.44) \\
7.27(4.24-12.47)\end{array}$ & $\begin{array}{c}- \\
<0.001 \\
<0.001 \\
<0.001 \\
<0.001 \\
<0.001\end{array}$ \\
\hline $\begin{array}{l}\text { Satisfaction } \\
\text { with the } \\
\text { monthly } \\
\text { income }\end{array}$ & $\begin{array}{l}\text { Very low } \\
\text { Low } \\
\text { Medium } \\
\text { High } \\
\text { Very high }\end{array}$ & $\begin{array}{l}234(49.5) \\
251(31.6) \\
173(25.1) \\
12(27.9) \\
2(22.2)\end{array}$ & $\begin{array}{c}1 \text { (Reference) } \\
0.47(0.37-0.60) \\
0.34(0.27-0.44) \\
0.39(0.20-0.79) \\
0.29(0.06-1.42)\end{array}$ & $\begin{array}{c}- \\
<0.001 \\
<0.001 \\
0.008 \\
0.127\end{array}$ & $\begin{array}{c}1 \text { (Reference) } \\
0.68(0.52-0.89) \\
0.57(0.42-0.76) \\
0.89(0.40-1.99) \\
0.42(0.07-2.38)\end{array}$ & $\begin{array}{c}- \\
0.006 \\
<0.001 \\
0.779 \\
0.127\end{array}$ \\
\hline $\begin{array}{l}\text { Marital } \\
\text { status }\end{array}$ & $\begin{array}{l}\text { Single (Never married, divorced } \\
\text { or widowed) } \\
\text { Married }\end{array}$ & $\begin{array}{l}179(50.9) \\
493(29.7)\end{array}$ & $0.41(0.32-0.52)$ & $<0.001$ & $1.00(0.71-1.41)$ & 0.993 \\
\hline $\begin{array}{l}\text { Level of } \\
\text { education }\end{array}$ & $\begin{array}{l}\text { Illiterate } \\
\text { Primary school } \\
\text { High school } \\
\text { College education }\end{array}$ & $\begin{array}{c}515(42.8) \\
103(24.0) \\
43(16.8) \\
11(9.1)\end{array}$ & $\begin{array}{c}1 \text { (Reference) } \\
0.42(0.33-0.54) \\
0.27(0.19-0.38) \\
0.13(0.07-0.25)\end{array}$ & $\begin{array}{l}<- \\
<0.001 \\
<0.001 \\
<0.001\end{array}$ & $\begin{array}{c}1 \text { (Reference) } \\
0.64(0.48-0.85) \\
0.57(0.38-0.85) \\
0.42(0.21-0.85)\end{array}$ & $\begin{array}{c}- \\
0.002 \\
0.006 \\
0.016\end{array}$ \\
\hline $\begin{array}{l}\text { Living } \\
\text { status }\end{array}$ & $\begin{array}{l}\text { Living with others } \\
\text { Living alone }\end{array}$ & $\begin{array}{l}583(32.1) \\
89(45.4)\end{array}$ & $1.76(1.30-2.37)$ & $<0.001$ & $1.00(0.71-1.41)$ & 0.020 \\
\hline Occupation & $\begin{array}{l}\text { Housewife or unemployed } \\
\text { Farmer or worker } \\
\text { Employee or retired } \\
\text { Other }\end{array}$ & $\begin{array}{c}545(50.0) \\
31(14.2) \\
65(14.0) \\
31(13.00) \\
\end{array}$ & $\begin{array}{c}1 \text { (Reference) } \\
0.17(0.11-0.25) \\
0.16(0.12-0.22) \\
0.15(0.10-0.22)\end{array}$ & $\begin{array}{c}- \\
<0.001 \\
<0.001 \\
<0.001\end{array}$ & $\begin{array}{c}1 \text { (Reference) } \\
0.34(0.21-0.55) \\
0.53(0.35-0.78) \\
0.40(0.25-0.65)\end{array}$ & $\begin{array}{c}- \\
<0.001 \\
0.002 \\
<0.001\end{array}$ \\
\hline
\end{tabular}




\section{Discussion}

According to the findings of this study, the prevalence rates of frailty and pre-frailty in older adults in Amirkola, north of Iran, were determined at $33.4 \%$ and $43.5 \%$, respectively. This result is nearly similar to the finding of a study carried out by Alqahtani et al. in Saudi Arabia with a reported frailty prevalence of $28 \%$ (19) and that of a study performed by Akin et al. in Turkey (27.8\%) (20). In a study carried out by Eyigor in Turkey, the prevalence rates of frailty and pre-frailty based on the hospitalbased data were reported as $39.2 \%$ and $43.3 \%$, respectively (21). Furthermore, Cakmur performed a study in rural areas of Turkey (22) and estimated the prevalence of frailty at $7 \%$, which could be due to higher physical activity of this rural population, relatively younger age, group living in this region, and better economic status of the mentioned people. The prevalence rate of frailty in the present study was lower than that $(47 \%)$ obtained by Kuwaiti et al. in the United Arab Emirates (UAE) (23) and the prevalence rate of $65 \%$ determined by Yadav et al. in Nepal (24). The higher prevalence of frailty in a study conducted by Yadav study can be attributed to the poverty and low socioeconomic status of the people, depression, low social support, and low level of physical activity in that region (24). In addition, in a study carried out by Khamis et al. in south Lebanon, the prevalence of frailty using the Groningen Frailty Indicator was reported as $81.3 \%$ (25).

Literature review represented a lower prevalence of frailty syndrome in some other countries. Martins et al. conducted a study in Japan and reported a prevalence rate of $13.5 \%$ in this regard (26). Moreover, the prevalence rates of frailty were estimated at $5.7 \%$ and $3.0 \%$ in the studies conducted by Vaingankar et al. in Singapore (27) and Hanlon et al. in the UK on people aged 37-73 years, respectively (11). Such a difference in the prevalence of frailty syndrome can be due to different demographic and socioeconomic characteristics of the study population and different criteria used for the definition of FS. In the current study, older age, female gender, lower education level, lower-income satisfaction, marital status (single), living alone, and unemployment have been represented as the characteristics associated with frailty in older adults.

Older age has been reported as an effective indicator of frailty in evidence (20-23, 25-27). The mean age of the study population affected the prevalence of frailty. The lower prevalence of frailty in some literature was attributed to the lower age of the participants, compared to similar studies $(11,22)$. It is noteworthy to mention that aging has an impact on other variables, such as lifestyle behaviors, physical activity, comorbid diseases, depressed mood, and resolution to homeostasis following stressor events (11).
According to the results, frailty was more common in females, which was consistent with the findings of previous studies $(23,25,28-31)$. In a study carried out by Thompson et al. in Australia, the prevalence of frailty in females was reported to be twice that of males (31).

Females show a higher percentage of frailty due to their longer life expectancy and consequent chronic disorders (25). Furthermore, lower muscle mass and strength, poorer nutritional status, and sarcopenia can be associated with a higher prevalence of FS in females (32). However, in the studies performed by Vaingankar et al. (27) and $\mathrm{Ng}$ et al. (33) (Singapore), as well as Cakmur (Turkey) (22), and Martins et al. (Japan) (26), there was no association between frailty and gender, which was not consistent with the findings in this study.

In the same vein, low education level was significantly associated with the prevalence of frailty in older adults. This finding is consistent with the results of other studies in the literature $(21,22,25$, $34,35)$; however, it is not in line with the findings of a study conducted in Belgium (36). Franse et al. reported the education level as one of the most consistently socioeconomic characteristics associated with frailty, morbidities, and self-rated health in adults aged 55 years and older (35). Since education level can be correlated with the level of health responsibility and self-care, self-efficacy, income, and socioeconomic status, the impact of the low education level on the prevalence of frailty can be justified $(34,37)$.

In our study, marital status (married) and living with a partner reduced the risk of frailty in older adults; however, the elderly living alone had a higher rate of frailty. This result is consistent with the findings of some other studies conducted by Hamidin et al. (Malaysia) (38), Kuwaiti et al. (the UAE) (23), and Pegorari et al. (Brazil) (39). On the other hand, it is not in line with the findings obtained by Eyigor et al. (21) and Runzer-Colmenares et al. (30). It seems that marital status (married) and living with a partner can improve the person's social support and reduce chronic diseases, cognitive disorders, depression, and occurrence of falls with an uncertain cause (40). To be socially isolated, lack of social attention and related economic characteristics might increase the occurrence of frailty syndrome in the elderly; in addition, divorce has been represented as an independent risk factor for the occurrence of frailty in some evidence $(28,37)$.

In the same line, lower-income satisfaction and unemployment increased the risk of frailty. This finding is in line with the results of the studies conducted by Khamis (south Lebanon) (25), Cakmur (Turkey) (22), Ocampo-Chaparro (Colombia) (41), and Yadav (Nepal) (24), where inappropriate socioeconomic status and insufficient current income has been represented as important factors to reduce the 
person's social support and predispose the person to frailty. Governmental policies and integrated programs for improving the socioeconomic status of adult people, especially middle-aged and older adults can prevent frailty in this population and promote healthy aging in different countries (42).

The most important strong point of the present study is the high participation rate of the elderly (2010 cases out of a total of 2135 elderly people). The cross-sectional design of this study is one of its limitations, and it is difficult to make a definite expression about the relationship between frailty and different characteristics.

\section{Conclusion}

One out of every three elderly people (aged $\geq 60$ ) in Amirkola, north of Iran, had frailty syndrome. Older age, female gender, lower education level, insufficient income satisfaction, marital status (single), living alone, and unemployment increased the risk of frailty in older adults.

\section{Footnotes}

Authors' Contribution: FTB, SRH, RG, and AB contributed to conception and design, acquisition of data, analysis and interpretation of data. SM drafted the article. All authors have read the manuscript, revised it critically for important intellectual content and approved the final version of the article to be published.

Conflict of Interests: The authors declare that they have no competing interests.

Ethical Approval: This study has been approved by the Ethics Committee of Babol University of Medical Sciences, Babol, Iran (ID: IR.MUBABOL.HRI.REC. 1397.144). All participants provided a written informed consent form to participate in the research.

Funding/Support: This study has been funded by the Babol University of Medical Sciences, Babol, Iran. Informed consent: All participants have been informed for personal characteristics or clinical details to be published in this study.

\section{References}

1. Wleklik M, Uchmanowicz I, Jankowska EA, Vitale C, Lisiak M, Drozd M, et al. Multidimensional approach to frailty. Front Psychol. 2020;11:564. doi: 10.3389/fpsyg.2020.00564. [PubMed: 32273868].

2. Chen X, Mao G, Leng SX. Frailty syndrome: an overview. Clin Interv Aging. 2014;9:433-41. doi: 10.2147/CIA.S45300. [PubMed: 24672230].

3. Uchmanowicz I, Lisiak M, Wleklik M, Gurowiec P, KałużnaOleksy $M$. The relationship between frailty syndrome and quality of life in older patients following acute coronary syndrome. Clin Interv Aging. 2019;14:805-16. doi: 10.2147/ CIA.S204121. [PubMed: 31190767].

4. Khezrian M, Myint PK, McNeil C, Murray AD. A review of frailty syndrome and its physical, cognitive and emotional domains in the elderly. Geriatrics (Basel). 2017;2(4):36. doi: 10.3390/geriatrics2040036. [PubMed: 31011046].

5. Kojima G, Liljas AEM, Iliffe S. Frailty syndrome: implications and challenges for health care policy. Risk Manag Healthc Policy. 2019;12:23-30. doi: 10.2147/RMHP.S168750. [PubMed: 30858741].

6. Ofori-Asenso R, Chin KL, Mazidi M, Zomer E, Ilomaki J, Zullo $A R$, et al. Global incidence of frailty and prefrailty among community-dwelling older adults: a systematic review and meta-analysis. JAMA Netw Open. 2019;2(8):e198398. doi: 10.1001/jamanetworkopen.2019.8398. [PubMed: 31373653].

7. Pengpid S, Peltzer K. Prevalence and associated factors of frailty in community-dwelling older adults in Indonesia, 20142015. Int J Environ Res Public Health. 2019;17(1):10. doi: 10.3390/ijerph17010010. [PubMed: 31861327].

8. Siriwardhana DD, Hardoon S, Rait G, Weerasinghe MC, Walters KR. Prevalence of frailty and prefrailty among communitydwelling older adults in low-income and middle-income countries: a systematic review and meta-analysis. BMJ Open. 2018;8(3):e018195. doi: 10.1136/bmjopen-2017-018195. [PubMed: 29496895].

9. Faller JW, Pereira DN, de Souza S, Nampo FK, Orlandi FS, Matumoto S. Instruments for the detection of frailty syndrome in older adults: a systematic review. PLoS One. 2019; 14(4):e0216166. doi: 10.1371/journal.pone.0216166. [PubMed: 31034516].

10. Cunha AIL, Veronese N, de Melo Borges S, Ricci NA. Frailty as a predictor of adverse outcomes in hospitalized older adults: a systematic review and meta-analysis. Ageing Res Rev. 2019;56:100960. doi: 10.1016/j.arr.2019.100960. [PubMed: 31518686].

11. Hanlon P, Nicholl BI, Jani BD, Lee D, McQueenie R, Mair FS. Frailty and pre-frailty in middle-aged and older adults and its association with multimorbidity and mortality: a prospective analysis of 493737 UK Biobank participants. Lancet Public Health. 2018;3(7):e323-32. doi: 10.1016/S24682667(18)30091-4. [PubMed: 29908859].

12. Bijani A, Ghadimi R, Mikaniki E, Kheirkhah F, Mozaffarpur SA, Motallebnejad M, et al. Cohort profile update: the Amirkola health and ageing project (AHAP). Caspian J Intern Med. 2017;8(3):205-12. doi: 10.22088/cjim.8.3.205. [PubMed: 28932373].

13. Alizadeh L, Salehi L. Older people's perspectives on health, physical activity and nutritional behaviors. Health Promot Perspect. 2015;5(4):288-95. doi: 10.15171/hpp.2015.034. [PubMed: 26933648].

14. Shamsabadi A, Delbari A, Sadr AS, Mehraeen E, Mohammadzadeh N, Niakan Kalhori SR. Questionnaire development and validation for designing a health telemonitoring system for frail elderly people. Digit Health. 2019;5:2055207619838940-. doi: 10.1177/2055207619838940. [PubMed: 30944727].

15. Mazoochi F, Gobbens RJ, Lotfi MS, Fadayevatan R. Diagnostic accuracy of the Tilburg frailty indicator (TFI) for early frailty detection in elderly people in Iran. Arch Gerontol Geriatr. 2020;91:104187. doi: 10.1016/j.archger.2020.104187. [PubMed: 32777633].

16. Hosseini SR, Cumming RG, Kheirkhah F, Nooreddini H, Baiani M, Mikaniki E, et al. Cohort profile: the Amirkola Health and Ageing Project (AHAP). Int J Epidemiol. 2014;43(5):1393-400. doi: 10.1093/ije/dyt089. [PubMed: 23918798].

17. Gleason LJ, Benton EA, Alvarez-Nebreda ML, Weaver MJ, Harris MB, Javedan H. FRAIL questionnaire screening tool and shortterm outcomes in geriatric fracture patients. J Am Med Dir Assoc. 2017;18(12):1082-6. doi: 10.1016/j.jamda.2017.07.005. [PubMed: 28866353].

18. Fried LP, Tangen CM, Walston J, Newman AB, Hirsch C, Gottdiener J, et al. Frailty in older adults: evidence for a phenotype. J Gerontol A Biol Sci Med Sci. 2001;56(3):M146-56. doi: 10.1093/gerona/56.3.m146. [PubMed: 11253156].

19. Alqahtani BA, Nasser TA. Assessment of frailty in Saudi community-dwelling older adults: validation of measurements. Ann Saudi Med. 2019;39(3):197-204. doi: 10.5144/02564947.2019.197. [PubMed: 31215244].

20. Akın S, Mazıcıoglu MM, Mucuk S, Gocer S, Deniz Şafak E, Arguvanlı $S$, et al. The prevalence of frailty and related factors 
in community-dwelling Turkish elderly according to modified Fried Frailty Index and FRAIL scales. Aging Clin Exp Res. 2015;27(5):703-9. doi: 10.1007/s40520-015-0337-0. [PubMed: 25762157].

21. Eyigor S, Kutsal YG, Duran E, Huner B, Paker N, Durmus B, et al. Frailty prevalence and related factors in the older adultFrailTURK Project. Age (Dordr). 2015;37(3):9791-. doi: 10.1007/s11357-015-9791-z. [PubMed: 25948502].

22. Çakmur H. Frailty among elderly adults in a rural area of Turkey. Med Sci Monit. 2015;21:1232-42. doi: 10.12659/MSM.893400. [PubMed: 25925800].

23. Al-Kuwaiti SJ, Aziz F, Blair I. Frailty in community-dwelling older people in Abu Dhabi, United Arab Emirates: a crosssectional study. Front Public Health. 2015;3:248. doi: 10.3389/fpubh.2015.00248. [PubMed: 26579508].

24. Yadav UN, Tamang MK, Thapa TB, Hosseinzadeh H, Harris MF, Yadav KK. Prevalence and determinants of frailty in the absence of disability among older population: a cross sectional study from rural communities in Nepal. BMC Geriatr. 2019;19(1):283. doi: 10.1186/s12877-019-1290-0. [PubMed: 31640571].

25. Khamis R, Sabbah H, Sabbah S, Peters L, Droubi N, Sabbah I. Evaluating the psychometric properties of the Arabic version of the Groningen frailty indicator among Lebanese elderly people. J Egypt Public Health Assoc. 2019;94(1):28. doi: 10.1186/s42506-019-0028-3. [PubMed: 32813111].

26. Arakawa Martins B, Visvanathan R, Barrie H, Huang $\mathrm{CH}$, Matsushita E, Okada K, et al. Frailty prevalence using Frailty Index, associated factors and level of agreement among frailty tools in a cohort of Japanese older adults. Arch Gerontol Geriatr. 2019;84:103908. doi: 10.1016/j.archger.2019.103908. [PubMed: 31319367].

27. Vaingankar JA, Chong SA, Abdin E, Picco L, Chua BY, Shafie S, et al. Prevalence of frailty and its association with sociodemographic and clinical characteristics, and resource utilization in a population of Singaporean older adults. Geriatr Gerontoly Int. 2017;17(10):1444-54. doi: 10.1111/ggi.12891. [PubMed: 27576598].

28. Jurschik P, Nunin C, Botigué T, Escobar MA, Lavedán A, Viladrosa M. Prevalence of frailty and factors associated with frailty in the elderly population of Lleida, Spain: the FRALLE survey. Arch Gerontol Geriatr. 2012;55(3):625-31. doi: 10.1016/j.archger.2012.07.002. [PubMed: 22857807].

29. Hoover M, Rotermann M, Sanmartin C, Bernier J. Validation of an index to estimate the prevalence of frailty among community-dwelling seniors. Health Rep. 2013;24(9):10-7. [PubMed: 24258362].

30. Runzer-Colmenares FM, Samper-Ternent R, Al Snih S, Ottenbacher KJ, Parodi JF, Wong R. Prevalence and factors associated with frailty among Peruvian older adults. Arch Gerontol Geriatr. 2014;58(1):69-73. doi: 10.1016/j.archger. 2013.07.005. [PubMed: 23978328].

31. Thompson MQ, Theou O, Karnon J, Adams RJ, Visvanathan R.
Frailty prevalence in Australia: findings from four pooled Australian cohort studies. Australas J Ageing. 2018;37(2):1558. doi: 10.1111/ajag.12483. [PubMed: 29314622].

32. Collard RM, Boter H, Schoevers RA, Oude Voshaar RC. Prevalence of frailty in community-dwelling older persons: a systematic review. J Am Geriatr Soc. 2012;60(8):1487-92. doi: 10.1111/j.1532-5415.2012.04054.x. [PubMed: 22881367].

33. Ng TP, Feng L, Nyunt MS, Larbi A, Yap KB. Frailty in older persons: multisystem risk factors and the Frailty Risk Index (FRI). J Am Med Dir Assoc. 2014;15(9):635-42. doi: 10.1016/j.jamda.2014.03.008. [PubMed: 24746590].

34. Heuberger RA. The frailty syndrome: a comprehensive review. J Nutr Gerontol Geriatr. 2011;30(4):315-68. doi: 10.1080/21551197.2011.623931. [PubMed: 22098178].

35. Franse CB, van Grieken A, Qin L, Melis RJF, Rietjens JA, Raat H. Socioeconomic inequalities in frailty and frailty components among community-dwelling older citizens. PLoS One. 2017;12(11):e0187946. doi: 10.1371/journal.pone.0187946. [PubMed: 29121677].

36. Joosten E, Demuynck M, Detroyer E, Milisen K. Prevalence of frailty and its ability to predict in hospital delirium, falls, and 6 month mortality in hospitalized older patients. BMC Geriatr. 2014;14(1):1. doi: 10.1186/1471-2318-14-1. [PubMed: 24393272].

37. Castell MV, Sánchez M, Julián R, Queipo R, Martín S, Otero Á. Frailty prevalence and slow walking speed in persons age 65 and older: implications for primary care. BMC Fam Pract. 2013;14(1):86. doi: 10.1186/1471-2296-14-86. [PubMed: 23782891].

38. Mohd Hamidin FA, Adznam SNA, Ibrahim Z, Chan YM, Abdul Aziz NH. Prevalence of frailty syndrome and its associated factors among community-dwelling elderly in East Coast of Peninsular Malaysia. SAGE Open Med. 2018;6: 2050312118775581. doi: 10.1177/2050312118775581. [PubMed: 29872529].

39. Pegorari MS, Tavares DM. Factors associated with the frailty syndrome in elderly individuals living in the urban area. Rev Lat Am Enfermagem. 2014;22(5):874-82. doi: 10.1590/01041169.0213.2493. [PubMed: 25493685].

40. Mouodi S, Bijani A, Hosseini SR, Hajian-Tilaki K. Gender differences in the health status of elderly living alone compared to those who are not alone: evidence of the AHAP study, North of Iran. Caspian J Intern Med. 2016;7(2):126-32. [PubMed: 27386065].

41. Ocampo-Chaparro JM, Reyes-Ortiz CA, Castro-Flórez X, Gómez F. Frailty in older adults and their association with social determinants of Health. The SABE Colombia Study. Colomb Med. 2019;50(2):89-101. doi: 10.25100/cm.v50i2.4121. [PubMed: 31607766].

42. Gu D, Yang F, Sautter J. Socioeconomic status as a moderator between frailty and mortality at old ages. BMC Geriatr. 2016;16:151. doi: 10.1186/s12877-016-0322-2. [PubMed: $27506542]$. 